\title{
Stress and Coping Strategies of High School Teachers of Antique Diocesan Catholic Schools
}

\author{
Hazel O. Lagos, MSLT ${ }^{1}$ and Celo I. Magallanes ${ }^{2}$ \\ ${ }^{1}$ St. Anthony's College, San Jose, Antique, Philippines \\ ${ }^{2}$ University of Negros Occidental-Recoletos, Bacolod City, Philippines
}

\begin{abstract}
Article history
Submitted: 11 July 2020

Revised: 26 October 2020

Accepted: 12 November 2020
\end{abstract}

Keywords

Guidance and Counseling

Stress

Coping Strategies

High School Teachers

Diocesan Catholic Schools

Antique
Introduction. No one is stress-free, no matter how fortunate, rational, intelligent, and knowledgeable he may be. Stress has almost become a sure thing even among Catholic school teachers. This is probably due to their demands for multiple jobs, teaching unmotivated students, maintaining classroom discipline, demanding workload, being subjected to frequent changes, being judged by others, having difficult or frustrating relationships with colleagues and administrators, and poor working conditions. Stressors faced by one teacher are unique to him or her and depend on factors like personality, beliefs, abilities, and circumstances of the teacher. Other variables, such as coping mechanisms and techniques, personality traits, and environmental characteristics, can interactively influence the teacher's understanding of how stressful situations are. To deal with stressful events and relieve feelings of distress, teachers use coping methods. Rilveria (2018) identified nine coping strategies: cognitive reappraisal, social support, problem-solving, religiosity, tolerance, emotional release, overactivity, recreation, and substance use. It has been observed that Antique Diocesan Catholic School teachers often experience high levels of stress resulting from multiple job responsibilities; thus, the researcher was propelled to explore and understand more this construct.

Methods. This study employed a descriptive-comparative-correlational research design, particularly the use of survey questionnaires. Through stratified random sampling, 140 out of 218 total number of high school teachers of the diocesan schools in Antique for the school year 2019-2020 were selected as respondents. Two standardized questionnaires were used, the 10-item Perceived Stress Scale by Cohen (1994) to measure the teachers' level of stress and the 37-item Filipino Coping Strategies Scale by Rilveria (2018) to measure the teachers' coping strategies. Furthermore, Mean, Standard Deviation, Mann Whitney $U$ test, Kruskal-Wallis, and Spearman rank correlation were utilized to analyze the data.

Results. The findings of the study revealed that the extent of stress as a whole is high. When the teachers were grouped according to age, teaching experience, and educational attainment, younger teachers, baccalaureate degree holders, and those with shorter teaching experienced a higher extent of stress than their counterparts. Teachers generally resort more to cognitive appraisal, problemsolving, and religiosity to cope with emotional release and overactivity. There is a significant difference in the extent of stress experienced and coping level when teachers were grouped according to age. Younger teachers are more stressed and engage more in coping strategies than older teachers. Furthermore, there was no significant difference in the extent of stress and coping level when high school teachers were grouped according to the length of service, sex, teaching load, and educational attainment. The study's findings revealed a significant relationship between the extent of stress and the extent of coping. This means that the more stressed teachers are, the more they engage in coping strategies to ease their stress, anxiety, and worries.

Conclusion. Like other teachers, the high school teacher-respondents were not spared from experiencing stress. It means that teaching can be a very challenging task in the life of educators. However, even if teachers were facing challenges in their teaching jobs, they still find ways to seek solutions to meet these challenges, such as having a changing view or assumptions about the problem, planning and taking action to confront the source of stress, or aiming to eliminate the 
stressor, and developing a deeper relationship with God, leaving everything to Him. Additionally, they also engage in other coping behaviors to keep everything in place. Finally, it is concluded that the higher the extent of stress experienced by teachers, the higher is the extent of their engagement with coping strategies. Recommendations can also be drawn from the findings, such as providing teachers with opportunities to promote lifelong learning in practical stress-reduction strategies, skill-sharing, and stress management workshops.

Practical Value of the Paper. This study may benefit school administrators, guidance counselors, human resource personnel, and teachers in designing a proposed stress management program that will help teachers learn about strategies in coping with stress. Likewise, this study's findings may guide future researchers to conduct similar studies to a larger sample in different contexts to validate or refute the findings of the study.

\section{References}

Admiraal, W. F., Korthagen, F. A., \& Wubbels, T. (2000). Effects of Student Teachers' Coping Behaviour. British Journal of Educational Psychology, 70(1), 33-52.

Antoniou, A. S., Ploumpi, A., \& Ntalla, M. (2013). Occupational Stress and Professional Burnout in Teachers of Primary and Secondary Education: The Role of Coping Strategies. Psychology, 4(03), 349.

Cohen, S., Kamarck, T., \& Mermelstein, R. (1994). Perceived Stress Scale. Measuring Stress: A Guide for Health and Social Scientists, 10, 1-2.

Eres, F. \& Atanasoska, T. (2011). Occupational Stress of Teachers: A Comparative Study between Turkey and Macedonia. International Journal of Humanities and Social Science, 1(7), 59-65.

Harris, C., Daniels, K., \& Briner, R. B. (2004). How do Work Stress and Coping Work? Toward a Fundamental Theoretical Reappraisal. British Journal of Guidance \& Counselling, 32(2), 223-234.

Kyriacou, C. (2001). Teacher Stress: Directions for Future Research. Educational Review, 53(1), 27-35

Lazarus, R. S. (2006). Emotions and Interpersonal Relationships: Toward a Person-centered Conceptualization of Emotions and Coping. Journal of Personality, 74(1), 9-46.

Mazo, G. N. (2015). Causes, Effects of Stress, and the Coping Mechanism of the Bachelor of Science in Information Technology students in a Philippine University. Journal of Education and Learning, 9(1), 71-78.

Mondal, J., Shrestha, S., \& Bhaila, A. (2011). School Teachers: Job Stress and Job Satisfaction, Kaski, Nepal. International Journal of Occupational Safety and Health, 1(1), 27-33.

Rilveria, J. R. C. (2018). The Development of the Filipino Coping Strategies Scale. Asia-Pacific Social Science Review. 18. 111-126.

\section{Correspondence:}

Hazel O. Lagos, MSLT [lagos08hazel@gmail.com]

https://orcid.org/0000-0003-4242-463X 